\title{
Finite Element Method for predicting rutting depth of steel deck asphalt pavement based on Accelerated Pavement Test
}

\author{
Huang Wen-ke ${ }^{a^{\star}}$, Zhang Xiao-ning, Rong Hong-liu, Chen Bo \\ School of Civil Engineering and Transportation, South China University of Technology, Guangzhou \\ 510640, China \\ $\mathrm{a}^{\star} 846247234 @ q q . c o m$
}

Keywords: steel deck pavement; rutting, Accelerated Pavement Test, Finite Element Method.

\begin{abstract}
Rutting is one of the most challenging and important distresses in steel deck pavement. The prediction of rutting depth is considered to be one of the most complex issues in pavement engineering. In this study, a large piece of linear track accelerated loading facility MLS66 was used to conduct the test on rutting at temperature $60^{\circ} \mathrm{C}$. To predict the behaviors of steel deck pavement, three-dimension FE model of the bridge is used in simulation. The time-hardening version of power-law model is used to investigate the rutting behaviors of steel deck pavement. A uniaxial compression creep test was applied to research on the creep characteristics of two adopted paving materials at temperature $60^{\circ} \mathrm{C}$. According to the test results, the nonlinear curve fitting software of OriginPro 8.0 is used to obtain the creep parameters based on power law creep model. Then, immediate and statistical loading is adopted for FE prediction instead of moving loading. Comparisons of the FE prediction with the results of full-scale testing have been presented, and fairly good results have been obtained.
\end{abstract}

\section{Introduction}

Rutting is one of the major distresses found in asphalt pavement especially when the temperature is high during the summer months [1]. It results from the accumulation of permanent deformation developed from all individual pavement layers. The width and depth of the rutting are widely affected by the structural characteristics of the pavement layers, traffic loads and environmental conditions.

The prediction of asphalt pavement structure rutting is considered to be one of the most complex issues in pavement engineering. Some analytical method researches were carried out to predict the rutting depth of asphalt pavement structure. The Mechanistic-Empirical Pavement Design Guide (MEPDG) design approach developed under NCHRP 1-37A uses performance prediction equations to evaluate the rutting of HMA [2, 3]. Safwat et al. evaluated an analytical approach based on a linear viscoelastic model for predicting permanent vertical strain in AC layers subjected to a moving load. The approach is verified by a full-scale accelerated loading test at different temperature [4]. Zhu et al. presents a rutting prediction method of asphalt pavement based on the two-stage viscoelastic-viscoplastic damage constitutive model along with a loading equivalence method. Laboratory wheel tracking tests under different temperatures, different loading levels, and step variable amplitude loads were conducted to evaluate the efficiency of rutting prediction. The results indicate that the rutting prediction method can effectively represent the rutting developing rules under standard loading and complicated variable amplitude loading with reliable prediction accuracy [5]. Choia et al. used a mechanistic permanent deformation model (shift model) to predict rutting depths of asphalt pavement. The model can successfully evaluate rutting depth, which proves the capability of the model implemented in the layered viscoelastic asphalt pavement analysis for critical distresses (LVECD) program [6].

Finite Element methods were successfully used to simulate complex pavement problems. Due to various advantages of finite element methods, many FE studies have been conducted to simulate and understand the performance of asphalt surfacing structure, so as to improve the design of pavement structure. Huurman et al. have reported that 3D-FEM can be used to estimate the 
behaviors of asphalt surfacing on orthotropic steel deck [7, 8]. Liu et al. developed a 3D finite element model subjected to stationary and moving loads to evaluate the characterization of membrane material connecting mastic asphalt surfacing to plates of orthotropic steel deck bridge [9]. Chazallon et al. presented a finite element program incorporating a permanent deformation model based on the concept of the shakedown theory developed by Zarka for the modeling of rutting of flexible pavements. They used the FE model to determine the stress field in the pavement. Then stress paths are derived and used to calculate the permanent deformations and displacement using a Drucker-Prager yield surface [10]. Ali et al. used finite-element model to analysize the rutting of urban pavements by taking into account the nonlinear behaviour of the pavement materials and the complex traffic conditions. After checked over full-scale pavement tests, The model is used for analysis of rutting in urban pavements and for the analysis of rehabilitation methods [11]. Wu et al. implemented a unified permanent deformation model developed for various pavement materials into the ABAQUS program through a UMAT subroutine to predict the rutting depths of two selected low-volume roads. Good agreement was found between the predicted and measured data [12]. Al-Rub et al. evaluated the effects of different simplified 2D and more realistic 3D loading techniques on predicting rutting in asphalt pavement under repeated loading conditions. Results show that the 2D plane strain FE simulations significantly overestimate rutting as compared with the rutting performance predictions from more realistic 3D FE simulations [13]. Al-Khateeb et al. developed a two-dimensional finite element model to investigate the impact of static repeated wheel load on rutting formation and pavement response. The sensitivity analysis indicated that the rutting depth increases with the increasing temperature and the tire pressure and with the decreasing subgrade strength [14]. Li et al. utilized specialized material models for asphalt layers and interface layers developed at Delft University of Technology with the numerical platform CAPA-3D to simulate the orthotropic steel deck bridge subjected to a moving load, then discussed the simulation result of distributed strain and temperature influence [15]. Arabani et al. used a 2D finite element modeling to predict the glasphalt mixture rutting behaviour and outputs of the model are compared with the experimental observations. The results show that the presented model can properly characterize rutting behavior of glasphalt mixtures [16].

The main objective of this paper is to establish a reliable finite element model to predict the rutting depth of an orthotropic steel deck pavement. In this paper, a prototype of an orthotropic steel deck bridge was tested with the accelerated pavement testing facility MLS66. Furthermore, a uniaxial compression creep test was applied to evaluate the creep characteristics of two adopted paving materials at temperature $60^{\circ} \mathrm{C}$ and creep parameters of asphalt pavement implemented into the ABAQUS program will be introduced in details. Comparisons of simulation predictions and field measurements are presented.

\section{Accelerated pavement test}

Hong Kong-Zhuhai-Macao Bridge is a very large sea-crossing bridge under construction in China. The main construction of the bridge will include a $15.8 \mathrm{~km}$-long continuous steel box girder span [17]. The bridge locates in a rainy and high-temperature area and steel deck pavement will be affected by complex natural environment and support heavy traffic load. So, high-temperature performance of asphalt pavement material will be of a high standard. Therefore, more high-temperature performance researches of asphalt pavement are needed.

\subsection{Testing Bridge}

For full-scale experiments in the MLS66 facility, an orthotropic steel bridge test panel is available. The testing bridge has a dimension of $8000 \times 3300 \times 1680 \mathrm{~mm}$ in length , width and height respectively. Supporting length along the bridge span direction and supporting width along the width direction of the bridge are $250 \mathrm{~mm}$ and $2085 \mathrm{~mm}$, respectively [18]. Earth anchorage supporting condition is applied to the end of the testing bridge. Due to the symmetry of geometry, only half the width of bridge was built. 


\subsection{Materials}

Asphalt binder of mastic asphalt was obtained by blending the pure asphalt A-70 and Trinidad Lake Asphalt (TLA). Combination of the British standards (BS6925:1988) and successful cases of steel bridge deck pavement in Hong Kong, the optimum ratio of A-70 to TLA is 3:7 (30\%A-70+70\%TLA). The mixture ratio of MA was determined by the graded mixture reports of Stonecutters' Bridge and Tsing Ma Bridge in Hong Kong provided by Anderson Asphalt limited. The mixture ratio of MA is given in Table 1. The aggregates of SMA-13 were graded using the technical specifications for construction of highway asphalt pavements (JTG F40-2004) as presented in Table 2.

Table 1 the mixture ratio of MA

\begin{tabular}{cccccccc}
\hline \multirow{2}{*}{ Sieve pore } & $\begin{array}{c}\text { Coarse aggregate } \\
\text { ratio (\%) }\end{array}$ & \multicolumn{5}{c}{ Fine aggregate ratio (\%) } & $\begin{array}{c}\text { Dosage of A-70 } \\
\text { and TLA asphalt } \\
\text { binder (\%) }\end{array}$ \\
\cline { 3 - 6 } & 2.36 & 0.6 & 0.212 & 0.075 & $<0.075$ & 17 \\
\hline Superior limit & 55 & 2.5 & 21 & 32 & 25 & 56 & 14 \\
Inferior limit & 35 & 0 & 4 & 8 & 8 & 40 & 15.3 \\
mixture ratio & 45 & 0.0 & 9.0 & 21.0 & 23.0 & 47.0 & 0 \\
\hline
\end{tabular}

Table 2 the mixture ratio of SMA-13

\begin{tabular}{ccccccccccccc}
\hline \multirow{2}{*}{ Sieve pore } & \multicolumn{10}{c|}{ Aggregate ratio (\%) } & $\begin{array}{c}\text { Dosage of } \\
\text { asphalt binder } \\
\text { nyyyyyy }\end{array}$ \\
\hline Superior limit & 1 & 13.2 & 9.5 & 4.75 & 2.36 & 1.1 & 0.6 & 0.3 & 0 & 0.007 & \\
Inferior limit & 100 & 90 & 75 & 34 & 26 & 24 & 20 & 16 & 15 & 12 & \\
mixture ratio & 100 & 97.6 & 62.1 & 26 & 15 & 14 & 12 & 10 & 9 & 8 & $5.66 \%$ \\
\hline
\end{tabular}

\subsection{Full-scale testing results}

MLS66 (Mobile Load Simulator 66) is a facility for full-scale accelerated pavement testing. The linear track accelerated loading facility primarily consists of 6 groups of dual-wheel carriage. The orthotropic steel bridge test panel was surfaced with a 30mm thick mastic asphalt base course and a $40 \mathrm{~mm}$ thick SMA-13 surface course. Thereafter the accelerated testing was carried out on the panel at temperature $60^{\circ} \mathrm{C}$. Magnitude of wheel load was fixed $50 \mathrm{kN}$. The previous mechanical analysis shows that the bridge is in the most unfavorable loading state when the loading center locates above the web of testing bridge. So in this research, lateral wander was not adopted.

Permanent deformation of the deck pavement is accurately measured by profile-meter after loading for 5000 cycles, 10000 cycles, 20000 cycles, 30000 cycles and 50000cycles, respectively. The profile-meter is an instrument using displacement sensor to record cross-section rut. Only the total rutting depths were monitored and recorded during the full-scale testing. The cross-section rut of deck pavement is presented in Figure1.

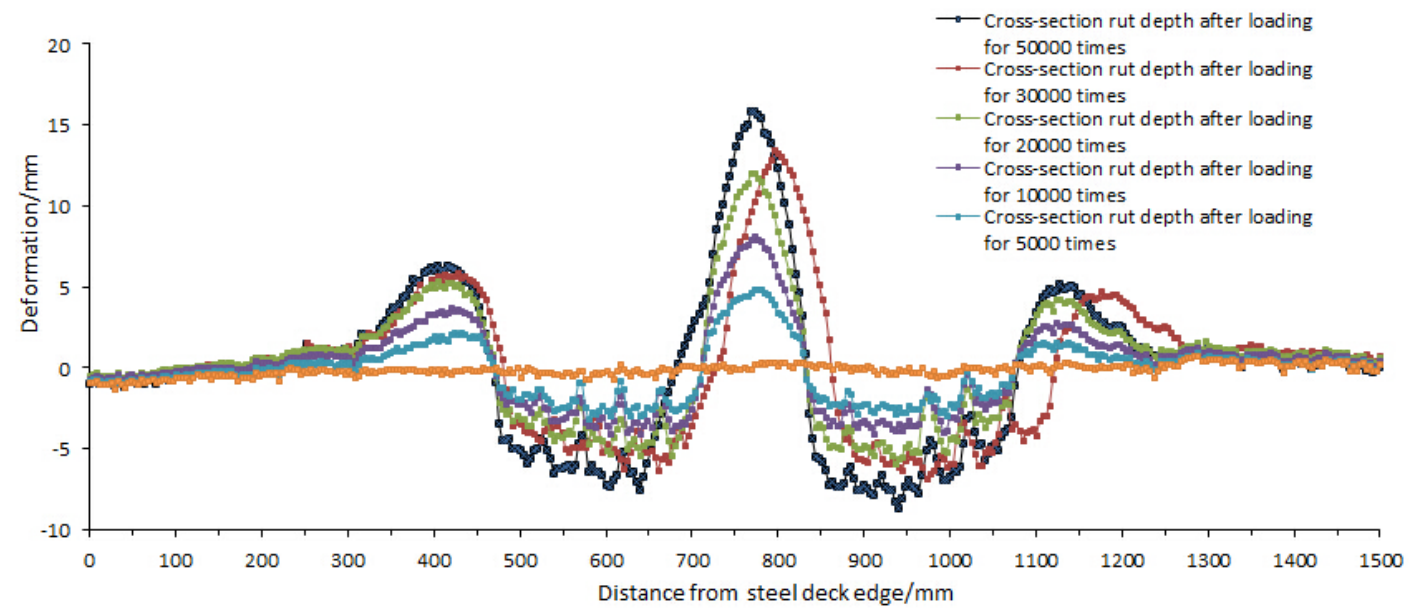

Fig.1 Cross-section of the rutting depth 


\section{Determination of required parameters for analysis in ABAQUS}

Asphalt mixture is a typical kind of rheological material. It has been proven that deformation of asphalt mixture can be reflected by creep models [19, 20, 21, 22, and 23].There are two kinds of creep models commonly used in ABAQUS, which are power-law model and hyperbolic-sine model. The power-law model includes time-hardening version as well as strain-hardening version. It is a relatively simple model but is considered appropriate for describing creep behaviors of asphalt mixture material $[1,16]$.

When variation of stress changes in a small range during a creep process, time-hardening version will be more appropriate. Differential expression of time-hardening version is given by [24]

$$
\dot{\bar{\varepsilon}}^{c r}=A \sigma^{n} t^{m}
$$

Where $\dot{\bar{\varepsilon}}^{\text {cr }}$ is the uniaxial equivalent creep strain rate, $\sigma$ is the uniaxial equivalent deviatoric stress, $\mathrm{t}$ is the total time. $A, n, m$ represents creep parameters, and $A>0, n>0,-1<m \leq 0$.

The direct integral expression of Eq. (1) is given by

$$
\varepsilon=\frac{A}{m+1} \sigma^{n} t^{m+1}
$$

To determine the creep parameters of mastic asphalt and SMA-13 in ABAQUS for analysis, a uniaxial static creep test was carried out on the asphalt concrete samples. Materials and mixture ratios used in the creep test are consistent with what was used in the full-scale testing. Referring to Standard Test Method for Compressive Strength of Bituminous Mixtures (ASTM D1074) and Compressive Strength of Cylindrical Concrete Specimens (AASHTO T22), the specimen has a diameter of $100 \mathrm{~mm}$ and specimen height is also100mm. Mastic asphalt specimens were cored from samples molded in $30 \times 30 \times 30 \mathrm{~cm}$ dimensions wooden boxes, and SMA-13 specimens were prepared by gyratory method in laboratory. The universal material tester MTS was applied to carry out the uniaxial static creep test at temperature $60^{\circ} \mathrm{C}$ in a temperature environmental cabinet. The constant loading velocity was $2 \mathrm{~mm} / \mathrm{min}$. The end faces of each specimen were coated with a thin lubricating membrane of polytetrafluoroethene in order to eliminate the influence of end face friction.

Testing stress levels should not be too big because of creep performance of mastic asphalt and SMA-13. In this paper creep tests were carried out with stress levels of $0.15 \mathrm{MPa}$ for mastic asphalt and 0.3MPa for SMA-13. The creep parameters in Eq. (2) can be developed from the uniaxial static creep test results through fitting Eq. (2) with OriginPro 8.0. Creep parameters are shown in Table 3. As can be easily understood from the calculated values of correlation coefficient, approximations are accurate and acceptable.

Table 3 Creep parameters

\begin{tabular}{cccccc}
\hline \multirow{2}{*}{$\begin{array}{c}\text { Type of mixture } \\
\text { asphalt }\end{array}$} & \multicolumn{3}{c}{ Creep parameters } & \multirow{2}{*}{ Variance } & $\begin{array}{c}\text { correlation } \\
\text { coefficient }\end{array}$ \\
\cline { 2 - 4 } & $\mathrm{A}$ & $\mathrm{n}$ & $\mathrm{m}$ & & 0.975 \\
SMA-13 & $9.67369 \mathrm{E}-4$ & 0.74596 & -0.77533 & $1.01 \mathrm{E}-7$ & 0.981 \\
\hline Mastic asphalt & 0.00304 & 0.61847 & -0.60038 & $8.14 \mathrm{E}-6$ & 0.96 \\
\hline
\end{tabular}

\section{Finite element simulation of steel deck asphalt pavement rutting}

To simulate the rutting behavior of steel deck pavement, the developed FE model in ABAQUS is shown in Figure 9 and Figure 10. Dimensions of the model are according to the full-scale testing bridge dimensions summarized in Table 1 . Elastic modulus of steel is $2.06 \times 10^{5} \mathrm{MPa}$ with a density of $7.85 \times 10^{-9}$ ton $/ \mathrm{mm}^{3}$. Weight of asphalt mixture is ignored. Because of the large numbers of element in the FE model, two kinds of element type are used for conducting FE simulations to improve the calculating speed. The element types for steel are four-node shell element with reduced integration (S4R) and for asphalt mixture eight-node brick element with reduced integration (C3D8R) is used. Thicknesses of mastic asphalt base course and SMA-13 surface course are 30mm and $40 \mathrm{~mm}$, respectively. The layer interface is simulated by the surface-to-surface contact model, 
assuming that there is no normal separation but frictional sliding is allowed at the interface.

The wheel loading area is assumed as a circular shape with a diameter of $213 \mathrm{~mm}$. Referring to a large number of calculations with finite element, the FE model is in the most unfavorable loading state when the dual-wheel load acts on mid-span of the bridge above the web. To simulate the loading mode of MSL66 shown in Figure 3, two dual-wheel groups are placed on the pavement surface of the FE model, and distance between the two wheel groups is $3080 \mathrm{~mm}$. Stress magnitude of each wheel is $0.7 \mathrm{MPa}$. Boundary conditions of the model are according to the full-scale testing bridge. Consolidation constraints are used on both ends of the model.

The FE modeling of real loading mechanism in a full-scale accelerated pavement testing is a complex process and its detailed modeling needs lots of time to be consumed. Thus, a simple method introduced and applied by Hua and Uzarowski was used in this research [25, 26].

In this modeling scheme, the load is immediately and statistically applied to the model. Then, the cumulative time is calculated based on the number of wheel passes. The required time the wheel needs to pass the path, is calculated based on wheel velocity and diameter of the assumed circular shape. The required time can be expressed by the equation:

$$
t=\frac{d}{V}
$$

Where $d$ is diameter of the assumed circular shape and $v$ is wheel velocity.

The wheel velocity of linear track accelerated loading facility MLS66 is $20 \mathrm{~km} / \mathrm{h}$. For circular diameter of $213 \mathrm{~mm}$, the cumulative time in one loading cycle is about 0.0384 s calculated by Eq. (3).

\section{Results and discussion}

The cumulative time of 192s, 383s, 767s, 1150s and 1917s were employed into ABAQUS as creep step increments to predict the creep deformation of the pavement. Experimental results and predicted results are summarized in Table 4.

Table 4 Comparison of experimental results and predicted results

\begin{tabular}{ccccccc}
\hline \multirow{2}{*}{ Comparison } & \multicolumn{5}{c}{ Loading cycles } \\
\cline { 3 - 7 } & $\begin{array}{c}\text { Rutting depth of } \\
\text { SMA-13 layer/mm }\end{array}$ & 3.924 & 4.077 & 4.144 & 4.223 & 4.304 \\
\hline $\begin{array}{c}\text { Simulation } \\
\text { results }\end{array}$ & $\begin{array}{c}\text { Rutting depth of MA } \\
\text { layer/mm }\end{array}$ & 7.553 & 7.571 & 8.667 & 9.145 & 9.762 \\
& $\begin{array}{c}\text { Total rutting depth } \\
\text { of pavement/mm }\end{array}$ & 11.477 & 11.648 & 12.811 & 13.368 & 14.066 \\
\multirow{2}{*}{$\begin{array}{c}\text { Experimental } \\
\text { results }\end{array}$} & $\begin{array}{c}\text { Total rutting depth } \\
\text { of pavement/mm }\end{array}$ & 8.409 & 9.957 & 12.763 & 14.192 & 16.481 \\
\multicolumn{1}{c}{ Tolerance /\% } & 36.48 & 16.98 & 0.38 & 5.81 & 14.65
\end{tabular}

As can be seen from Table 8, both of the full-scale testing results and the predicted results deepen along with loading cycles increasing. The results show that the FE model captures the general trend of the rutting behaviors of pavement structure subjected to traffic loading. Also, rutting mainly occurred at the MA layer, but very small deformation was observed at the SMA-13 layer. This observation is consistent with field cutting section of the pavement after full-scale testing. In other words, the SMA-13 layer has a high potential to resist pavement rutting. Thus, rutting resistance of the MA layer should be an important consideration in terms of pavement structure design.

There are some tolerances between the full-scale results and the predicted results. The conducted simulations show that rutting prediction in asphalt pavement significantly underestimate when the 
loading cycle number is small. It is because the steel deck pavement is in the process of compacting at the beginning of the full-scale testing, which creep performance is not obvious. In this process, rutting is related to the plastic deformation of asphalt concrete. Creep deformation of asphalt concrete, however, developed largely at the beginning of FE prediction. Thus the deformation of FE prediction is larger than that of full-scale testing. With the numbers of loading cycle increasing, the results calculated by ABAQUS almost approach to the full-scale testing values.

Another reason why there is tolerance between the full-scale testing results and the FE predicted results is that dynamic load is applied to the full-scale testing while immediate and statistical load is adopted for the FE prediction. Asphalt concrete is very sensitive to loading frequency. Elastic modulus of asphalt concrete varies a lot under different loading velocity. The elastic modulus adopted in ABAQUS, however, is a constant value, which leads to tolerances between the full-scale results and the predicted results. Furthermore, stress field simulated by finite element method is different from the realistic one tested at the accelerated pavement testing facility MLS66, which has an effect on the creep deformation performance of steel deck asphalt pavement.

In final, tolerances between the full-scale testing and the FE prediction are smaller than $17 \%$ when loading cycles are in the range of 10000 50000. By this value, it is conclude that the presented FE model used in this research has good validity to estimate high-temperature rutting depth of the steel deck pavement according to previous researches [16, 27].

\section{Summary and conclusions}

This paper describes the prediction of rutting based on finite element method. Three-dimension FE model is applied in simulation. The time-hardening version of power-law model is used to investigate the rutting behaviors of steel deck pavement. Initially, the creep parameters were developed from the uniaxial static creep tests. Then, in order to reduce computational cost, immediate and statistical loading is adopted for FE prediction instead of moving loading. Comparisons of the FE prediction with results of full-scale testing have been presented, and fairly good results have been obtained. Based on the material presented in this paper, the following conclusions can be drawn:

(1)Rutting mainly occurred at MA layer, but very small deformation was observed at SMA-13 layer. Rutting resistance of MA layer should be an important consideration in terms of the pavement structure design.

(2)Both of the full-scale testing results and predicted results become greater when loading cycles increase. The results show that the FE model captures the general trend of the rutting behaviors of the pavement structure subjected to traffic loading.

(3)Tolerances between full-scale testing and finite element prediction are smaller than $17 \%$ when loading cycles are in the range of 10000 50000. This results show that there is a good relationship between the rutting predicted in FE model and the rutting measured in the full-scale testing. Therefore, it is feasible to apply the finite element model to predict rutting behaviors of steel deck asphalt pavement.

\section{References}

[1] White T, Haddock J, Hang A, Fang H. Contributions of pavement structural layers to rutting of hot mix asphalt pavements. Transportation research board, NCHRP Report 468, Washington, D.C.; 2002.

[2] NCHRP. 2009a. NCHRP 1-37A Climate data, Washington, D.C.: American Association of State Highway and Transportation Officials.

[3] NCHRP. 2009b. NCHRP 1-37A Design guide software, Washington, D.C.: American Association of State Highway and Transportation Officials.

[4] Said S F, Hakim H, Oscarsson E, et al. Prediction of flow rutting in asphalt concrete layers[J]. 
International Journal of Pavement Engineering, 2011, 12(6): 519 532.

[5] Zhu H, Sun L. Mechanistic Rutting Prediction Using a Two-Stage Viscoelastic-Viscoplastic Damage Constitutive Model of Asphalt Mixtures[J]. Journal of Engineering Mechanics, 2013, 139(11): $1577 \sim 1591$.

[6] Choi Y, Kim Y R. Implementation and verification of a mechanistic permanent deformation model (shift model) to predict rut depths of asphalt pavement[J]. Road Materials and Pavement Design, 2014, 15(sup1): 195 218.

[7] M. Huurman, T.O. Medani, A.Scarpas, C.Kabergen, "3D-FEM for estimation of the behavior of asphalt surfacings on orthotropic steel deck bridges” International Conference on Computational and Experimental Engineering and Sciences, ICCES’03 Corfu, Greece, 24-29 July 2003.

[8] M. Huurman, T.O. Medani, A.A.A. Molenaar, C.Kasbergen, A.Scarpas, “APT testing and 3D finite element analysis of asphalt surfacings on orthotropic steel deck bridges”, 83rd Annual TRB Meeting, Washington, D.C., USA,2004.

[9] Liu X, Medani T O, Scarpas A, et al. Characterisation of surfacing materials for orthotropic steel deck bridges. Part 2: numerical work[J]. International Journal of Pavement Engineering, 2009, 11(3): $255 \sim 265$.

[10] Chazallon C, Koval G, Hornych P, et al. Modelling of rutting of two flexible pavements with the shakedown theory and the finite element method[J]. Computers and Geotechnics, 2009, 36(5): $798 \sim 809$.

[11] Ali B, Sadek M, Shahrour I. Finite-Element Model for Urban Pavement Rutting: Analysis of Pavement Rehabilitation Methods[J]. Journal of Transportation Engineering, 2009, 135(4): 235 239.

[12] Wu Z, Chen X, Yang X, et al. Finite Element Model for Rutting Prediction of Flexible Pavement with Cementitiously Stabilized Base-Subbase[J]. Transportation Research Record: Journal of the Transportation Research Board, 2011, 2226(-1): 104 110.

[13] Abu Al-Rub R K, Darabi M K, Huang C, et al. Comparing finite element and constitutive modelling techniques for predicting rutting of asphalt pavements[J]. International Journal of Pavement Engineering, 2011, 13(4): 322 338.

[14] Al-Khateeb L A, Saoud A, Al-Msouti M F. Rutting Prediction of Flexible Pavements Using Finite Element Modeling[J]. Jordan Journal of Civil Engineering, 2011, 2(5): 173 190 .

[15] Li J, Liu X, Scarpas A, et al, Numerical Simulations of Multilayer Surfacing Systems on Orthotropic Steel Deck Bridges. In; American Society of Civil Engineers: 2013; pp 1457 1469

[16] Arabani M, Jamshidi R, Sadeghnejad M. Using of 2D finite element modeling to predict the glasphalt mixture rutting behavior[J]. Construction and Building Materials, 2014, 68(0): 183 191 .

[17] South China University of Technology. Research of steel deck pavement for Hong Kong-Zhuhai-Macao Bridge [R]. Guangzhou: South China University of Technology, 2011.

[18] South China University of Technology. Accelerated loading test of steel deck pavement for Hong Kong-Zhuhai-Macao Bridge [R]. Guangzhou: South China University of Technology, 2012.

[19] Mahboub K. Asphalt Concrete Creep as Related to Rutting[J]. Journal of Materials in Civil Engineering, 1990, 2(3): $147 \sim 163$.

[20] Drescher A, Kim J, Newcomb D. Permanent Deformation in Asphalt Concrete[J]. Journal of Materials in Civil Engineering, 1993, 5(1): 112 128. 
[21] He G, Wong W. Laboratory study on permanent deformation of foamed asphalt mix incorporating reclaimed asphalt pavement materials[J]. Construction and Building Materials, 2007, 21(8): 1809 1819.

[22] Al-Qadi I, Yoo P, Elseifi M, et al. Creep Behavior of Hot-Mix Asphalt due to Heavy Vehicular Tire Loading[J]. Journal of Engineering Mechanics, 2009, 135(11): 1265 1273.

[23] Sohm J, Gabet T, Hornych P, et al. Creep tests on bituminous mixtures and modelling[J]. Road Materials and Pavement Design, 2012, 13(4): 832 849.

[24] Abaqus Analysis User’s Manual ,version 6.11. Dassault Systemes Simulia Corp., 2011.

[25] Hua J. Finite element Modeling and analysis of Accelerate Pavement Testing Devices and Rutting Phenomenon.Ph.D. Thesis, Purdue Univerdity; 2000.

[26] Uzaowski L, Paradis M, Lum P. Accelerated performance testing of Canadian asphalt mixes using three different wheel testers. Quebec: Transportation Association of Canada: 2004.

[27] Kandhal S, Cooley A. Accelerated laboratory rutting testes: evaluation of the asphalt pavement analyzer. NCHRP Report 508. Transportation research board, Washington, D.C.; 2003. 